\title{
Effects of grain size on the spallation behavior of pure copper under plate-impact loading
}

\author{
ZhaoXiu Jiang $^{1}$, Hui Peng ${ }^{2}$, MingZhi Xing ${ }^{1}$, HaiTing Shen ${ }^{1}$, HongLiang $\mathrm{He}^{2}$, and YongGang Wang ${ }^{1, \text { a }}$ \\ ${ }^{1}$ Key Laboratory of Impact and Safety Engineering, Ministry of Education of China, Ningbo University, \\ Zhejiang 315211, People's Republic of China \\ ${ }^{2}$ Key Laboratory for Shock Wave and Detonation Physics Research, Institute of Fluid Physics, China Academy of \\ Engineering Physics, Mianyang 621900, People’s Republic of China
}

\begin{abstract}
The effects of grain size on the dynamic tensile fracture (or spall) response were investigated for high purity copper materials by plate-impact experiments. The spall strength estimated from the free surface velocity profile is nearly constant with no significant effect from the grain size. However, differences are observed in the acceleration rate of velocity rebound beyond the minima. This may be attributed to the effect of grain size on the growth rate of damage. Metallographic analyses of the fracture surface show that the characteristic feature of the fracture surface clearly depends on the grain size. In the smaller samples, the fracture surfaces are decorated with large, high-density ductile dimples suggesting that the preferential failure mode is ductile intergranular fracture. In the larger samples, the fracture surfaces have a rock candy appearance with small, brittle, high density dimples as well as large ductile dimples suggesting that the fracture mode is a mix of both brittle intergranular fracture and ductile transgranular fracture.
\end{abstract}

\section{Introduction}

The dynamic tensile fracture (or spall) behaviors of metallic materials produced by the interaction of release waves after shock loading is a complicated physical process that can be strongly influenced by many variables related to the applied loading, temperature, and the material itself [1-4]. This extensive work has shown that the grain size plays an important role in spall failure. Because many parameters and mechanisms are intertwined, previous studies regarding grain size effects on spall behavior have reported different and sometimes contradictory results $[5,6]$. Recently, a comprehensive set of incipient spall experiments on copper was performed by Escobedo et al. [7]. The free surface velocity measurements show no significant grain size dependence on the spall strength of 30-, 60-, $100-$ and $200-\mu \mathrm{m}$ copper samples. However, there were obvious differences in the free surface velocity behavior after the pull-back velocity minima. This is attributed to the different active mechanisms of damage, some of which depend on the grain size and grain boundary types. To ensure a good correlation between a particular microstructural feature and the spall response, it is important that only one parameter be varied at a time. In this paper, plate impact experiments were performed on high purity copper samples to examine the relationship between grain size and spall response. In order to eliminate the effect of loading on spall behavior, the peak compressive stress and tensile strain rate in plate impact experiments are carefully controlled and held constant. The results are presented and discussed in terms of free surface velocity measurements

\footnotetext{
${ }^{a}$ Corresponding author: wangyonggang@nbu .edu.cn
}

as well as metallographic examinations of the spall surface with scanning electron microscopy (SEM).

\section{Experimental procedures}

\subsection{Materials}

Polycrystalline copper plate material with $99.99 \%$ purity was subjected to an additional cold-rolling procedure followed by recrystallization to produce a wide range of grain sizes. Samples were annealed in vacuum with furnace cooling at $500^{\circ} \mathrm{C}$ for 3.5 hours to produce an average grain size of $78 \mu \mathrm{m}, 700^{\circ} \mathrm{C}$ for 3.0 hours to produce a grain size of $273 \mu \mathrm{m}$, and $850^{\circ} \mathrm{C}$ for 3.0 hours to produce a grain size of $400 \mathrm{~m}$. Microstructural characterization of different heat-treated copper samples is shown in Fig. 1. The grain size was measured using the line intercept method.

\subsection{Plate-impact experiments}

A 57-mm light gas gun was used for the planar symmetrical impact spall experiments. The diameters of the flyer and the target are $50 \mathrm{~mm}$ and $35 \mathrm{~mm}$ with thicknesses of $3 \mathrm{~mm}$ and $6 \mathrm{~mm}$, respectively. Timeresolved free surface velocity profiles of the shocked sample were measured with a compact all-fiber single point displacement interferometer system for any reflector (DISAR) to monitor spall fracture [8]. A 1550-nm laser beam was used as the light source for the DISAR system. A single-mode 1-mm optic fiber pigtail was used to collect light reflected from the moving surface. The output DISAR signals were recorded using a high-frequency digital Tektronix with a time resolution of $0.5 \mathrm{~ns}$. To examine 


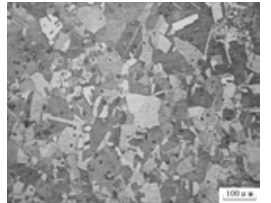

(a) $78 \mu \mathrm{m}$

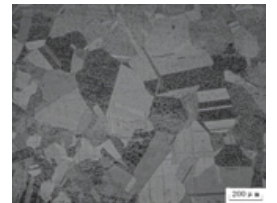

(b) $273 \mu \mathrm{m}$

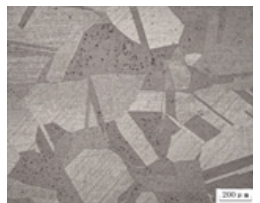

(c) $400 \mu \mathrm{m}$
Figure 1. Optical micrographs of high purity copper with the average grain sizes: (a) $78 \mu \mathrm{m}$, (b) $247 \mu \mathrm{m}$, and (c) $400 \mu \mathrm{m}$.

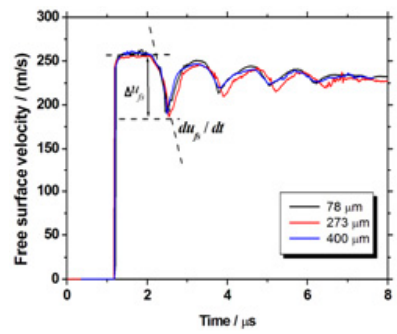

(a)

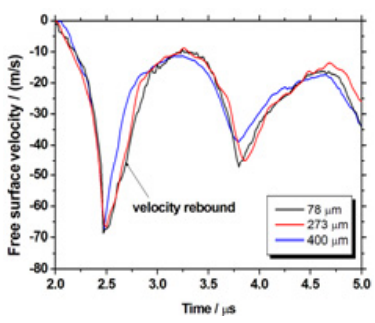

(b)
Figure 2. (a) Free surface velocity profiles for copper samples with different grain sizes. (b) Pullback wave measured at different grain sizes.

the metallographic characterization of the fracture surface, a soft recovery technique for the shocked specimen was adopted. All experimental conditions are listed in Table 1.

\section{Results and discussions}

\subsection{Free surface velocity profiles}

Figure 2(a) shows the measured free surface velocity profiles for the different grain size copper samples. The peak free surface velocities range from 254 to $258 \mathrm{~m} / \mathrm{s}$, corresponding to peak compressive stresses of 4.68-4.76 GPa. Figure 2(b) shows the free surface velocity profiles once significant yielding begins causing a drop in the free surface velocity. The times and velocities are shifted so that the drop from the peak state starts at $\mathrm{t}=$ 0 . From the slope of the drop in free surface velocity profiles (Fig. 2(a)) the tensile strain rate of $2.7 \times 10^{4} \mathrm{~s}^{-1}$ is estimated in all cases via [9]:

$$
\dot{\varepsilon}=\frac{1}{2 c_{0}} \frac{d u_{f s}}{d t}
$$

where $c_{0}=3940 \mathrm{~m} / \mathrm{s}$ is copper's bulk sound speed. The velocity difference between the first peak plateau and the first valley, commonly referred to as the pullback velocity $\left(\Delta u_{f s}\right)$, estimates the spall strength or stress threshold for fracture (Fig. 2(a)). For materials undergoing elasticplastic deformation either during compression or tension, the spall strength is calculated from the observed pullback velocity using [9]:

$$
\sigma_{s}=\rho_{0} c_{l} \Delta u_{f s}\left(1+\frac{c_{l}}{c_{0}}\right)^{-1}
$$

where $c_{l}=4770 \mathrm{~m} / \mathrm{s}$ is copper's longitudinal elastic wave speed. The measured and calculated key parameters are listed in Table 1. A spall strength of $1.29 \sim 1.33 \mathrm{GPa}$ was
Table 1. Summary of the experimental parameters and results.

\begin{tabular}{ccccc}
\hline \hline $\begin{array}{c}\text { Shot } \\
\text { No. }\end{array}$ & $\begin{array}{c}\text { Grain } \\
\text { size } \\
(\mu \mathrm{m})\end{array}$ & $\begin{array}{c}\text { Impact } \\
\text { velocity } \\
(\mathrm{m} / \mathrm{s})\end{array}$ & $\sigma_{c} / \mathrm{GPa}$ & $\sigma_{s} / \mathrm{GPa}$ \\
\hline 1 & 78 & 258 & 4.76 & 1.32 \\
2 & 273 & 254 & 4.68 & 1.29 \\
3 & 400 & 256 & 4.72 & 1.33 \\
\hline \hline
\end{tabular}

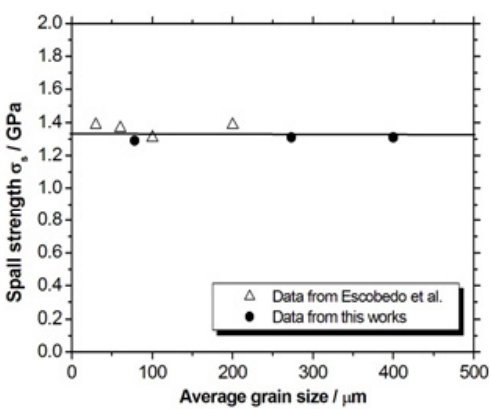

Figure 3. Spall strength as a function of the average grain size for pure copper materials.

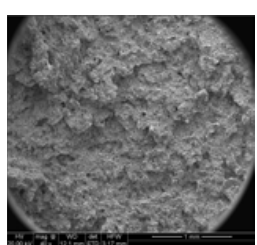

(a)

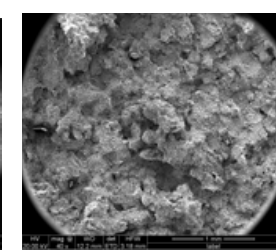

(b)

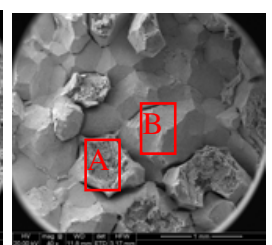

(c)
Figure 4. Scanning electron micrographs of the fracture surface at low magnification $(40 \times)$ : (a) $78 \mu \mathrm{m}$, (b) $273 \mu \mathrm{m}$ and (c) $400 \mu \mathrm{m}$.

calculated for different grain size samples by holding the loading profile constant, i.e., peak stress and tensile strain rate are the same for each experiment. Figure 3 shows the spall strength as a function of the average grain size for pure copper samples along with previous results from Escobedo et al., which indicates no significant effect of grain size on the spall strength.

\subsection{Post-impact metallurgical characterization}

Careful fractography of the recovered samples was conducted by SEM to illustrate the damage characteristics and fracture mechanism. Although grain size does not affect spall strength of the high purity copper, grain size does markedly influence the type of fracture surface produced during spall. Figure 4(a)-(c) shows SEM images of the fracture surface at low magnification $(40 \times)$ with different grain sizes. From Fig. 5(a) and (b), we see that the fracture surfaces of the $78-\mu \mathrm{m}$ and $273-\mu \mathrm{m}$ samples are completely decorated with high-density dimples indicative of microvoid coalescence. The fracture surface of the 400$\mu \mathrm{m}$ sample shown in Fig. 4(c) is mainly filled with rock candy-like grains and exhibits a mixture of brittle intergranular fracture facets and ductile transgranular fracture regions. The higher magnification image reveals a dimpled 


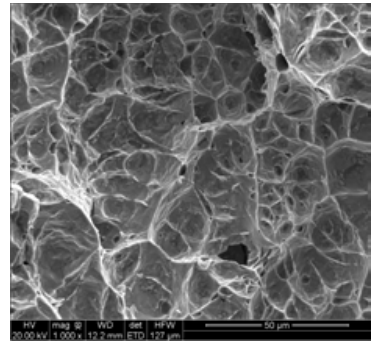

(a) $78 \mu \mathrm{m}$

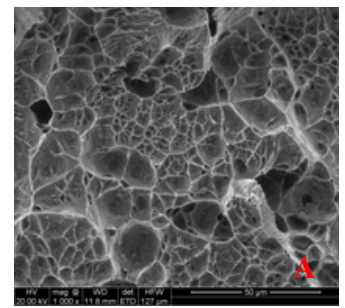

(c) $400 \mu \mathrm{m}$

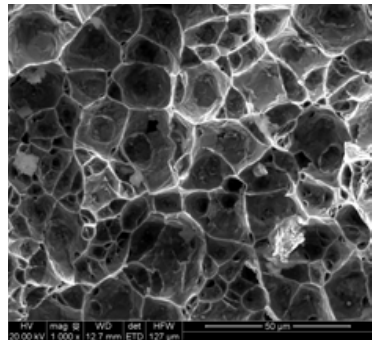

(b) $273 \mu \mathrm{m}$

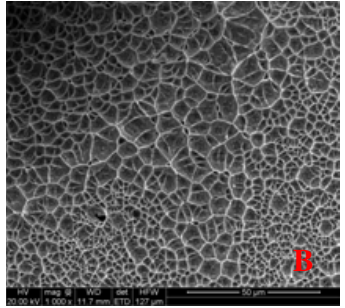
Figure 5. Scanning electron micrographs of the fracture surface
at high magnification $(1000 \times)$ : (a) $78 \mu \mathrm{m}$, (b) $273 \mu \mathrm{m}$ and (c) $400 \mu \mathrm{m}$.

topology on the grain facets. Figure 5(a)-(c) shows SEM images of the fracture surface at high magnification $(1000 \times)$ with different grain sizes. This illustrates the change of the dimple structure as a function of the grain sizes. For the samples with smaller grain size $(78 \mu \mathrm{m}$ and $273 \mu \mathrm{m})$, the fracture surfaces have larger ductile dimples. These are produced by microvoid coalescence along the grain boundaries, which indicates that the fracture is a ductile intergranular fracture. The dimple size (average diameter and average depth) of the $78-\mu \mathrm{m}$ sample is smaller than the $273-\mu \mathrm{m}$ sample. Void coalescence will be enhanced in a sample with relatively small grain sizes ( $78 \mu \mathrm{m}$ in this study) in which voids are nucleated on different grain boundaries and are close together. On the contrary, in samples with intermediate grain sizes $(273 \mu \mathrm{m})$, the voids can grow larger but remain isolated before void coalescence that results in larger dimples on the fracture surfaces. For the $400-\mu \mathrm{m}$ grain sample (Fig. 5(c)), the fracture surface has larger ductile dimples that suggest a ductile transgranular fracture mode (region A in Fig. 4(c)). In contrast, in region B of the same figure the fracture surface exhibits small, high density brittle dimples suggesting a brittle intergranular fracture mode.

Usually, voids preferentially nucleate along the grain boundaries, and grain boundaries are the preferred path for spall fracture. The reason for ductile transgranular fracture in coarse grain size samples is that the grain boundary area available for fracture near the spall plane decreases with increasing grain size. This forces the fracture to occur at large grain sizes. In other words, if the width of the tensile peak near the spall plane is smaller than the grain size, then a transgranular fracture is induced rather than an intergranular fracture. In turn, brittle intergranular fractures correspond to smaller dimples in coarse grain size samples because many voids are nucleated along the same grain boundary very close together. Thus, the void coalescence is strongly enhanced to restrain void growth.

\section{Conclusion}

Plate impact experiments and microscopic observations on post-impact recovered samples were used to study the influence of grain size on the dynamic tensile/spall behavior of high purity copper samples. By holding the loading conditions constant, the free surface velocity profiles were studied as a function of grain size. The spall strength estimated from the pullback velocity has no significant effect of the grain size. The post-impact metallographic analyses show that samples with smaller grain sizes $(78 \mu \mathrm{m}$ and $273 \mu \mathrm{m})$ have fracture behavior dominated by ductile intragranular fractures with many large ductile dimples on the fracture surface. In the $400-\mu \mathrm{m}$ samples, the fracture mode is dominated by a mixture of both brittle intergranular fractures and ductile transgranular fractures that combine smaller dimples with larger ductile dimples on the fracture surface.

This research was supported by the National Science Foundation of China under Grant No. 11272164, 11172221 and 11472142, and sponsored by K. C. Wong Magna Fund and K. C. Wong Eduation Fund in Ningbo University, China.

\section{References}

[1] D.D. Koller, R.S. Hixson, G.T. Gray III, P.A. Rigg, L.B. Addession, E.K. Cerreta, J. Appl. Phys. 98, 103518 (2005)

[2] Y.G. Wang, Z.X. Jiang, M.Z. Xing, L.L. Wang, Mater. Sci. Eng. A 596, 222 (2014)

[3] X.Chen, J.R. Asay, and S.K. Dwivedi, J. Appl. Phys. 99, 023528 (2006)

[4] C.L. Williams, K.T. Ramesh, and D.P. Dandekar, J.Appl.Phys. 111, 123528 (2012)

[5] S. Christy, H.R. Pak, and M.A. Meyers, in Metallurgical Applications of Shock-Wave and High-Strain-Rate Phenomena, edited by L.E. Murr, K.P. Staudhammer, and M.A. Meyers (Dekker, New York, NY, 1986), p. 835

[6] R.W. Minich, J.U. Cazamias, M. Kumar, and A.J. Schwartz, Metall. Mater. Trans. A 35, 2663 (2004)

[7] J.P. Escobedo, D. Dennis-Koller, E.K. Cerreta, B.M. Patterson, C.A. Bronkhorst, B.L. Hansen, D. Tonks, and R.A. Lebensohn, J. Appl. Phys. 110, 033513 (2011)

[8] J.D. Weng, X. Wang, Y. Ma, H. Tan, L.C. Cai, J.F. Li, C.L. Liu, Rev. Sci. Instru. 79, 113101 (2008)

[9] T. Antoun, L. Seaman, D.R. Curran, G.I. Kanel, S.V. Razorenov, A.V. Utkin, Spall Fracture (Springer, Berlin, 2003) 